\title{
(6) OPEN ACCESS \\ Prevention of neural tube defects in the UK: a missed opportunity
}

- Additional material is published online only. To view please visit the journal online (http://dx.doi.org/10.1136/ archdischild-2015-309226).

${ }^{1}$ Wolfson Institute of Preventive Medicine, Queen Mary University of London, London, UK

${ }^{2}$ Institute of Health \& Society, Newcastle University, Newcastle upon Tyne, UK ${ }^{3}$ Department of Epidemiology \& Public Health, University of Leicester, Leicester, UK

${ }^{4}$ National Perinatal Epidemiology Unit, University of Oxford, Oxford, UK

${ }^{5}$ Public Health England, London, UK

${ }^{6}$ Congenital Anomaly Register and Information Service for Wales, Public Health Wales, Swansea, UK

${ }^{7}$ University of Southampton and Wessex Clinical Genetics Service, Southampton, UK ${ }^{8}$ School of Clinical Sciences, University of Bristol, Bristol, UK

Correspondence to Professor Joan Morris, Wolfson Institute of Preventive Medicine, Queen Mary University of London, Charterhouse Square, London EC1M 6BQ, UK j.k.morris@qmul.ac.uk

Received 23 June 2015 Revised 13 October 2015 Accepted 17 October 2015 Published Online First 17 December 2015

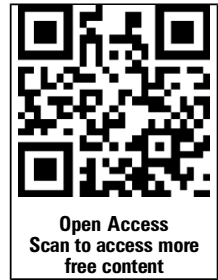

\section{SLinked}

- http://dx.doi.org/10.1136/ archdischild-2015-309983

\author{
JK Morris, ${ }^{1}$ J Rankin, ${ }^{2}$ ES Draper, ${ }^{3}$ JJ Kurinczuk, ${ }^{4,5}$ A Springett, ${ }^{1,5}$ D Tucker, ${ }^{6}$ \\ D Wellesley, ${ }^{7}$ B Wreyford, ${ }^{5,8}$ NJ Wald ${ }^{1}$
}

\section{ABSTRACT}

Objective In 1991, the Medical Research Council (MRC) Vitamin Study demonstrated that folic acid taken before pregnancy and in early pregnancy reduced the risk of a neural tube defect (NTD). We aimed to estimate the number of NTD pregnancies that would have been prevented if flour had been fortified with folic acid in the UK from 1998 as it had been in the USA.

Design Estimates of NTD prevalence, the preventive effect of folic acid and the proportion of women taking folic acid supplements before pregnancy were used to predict the number of NTD pregnancies that would have been prevented if folic acid fortification had been implemented.

Setting Eight congenital anomaly registers in England and Wales.

Main outcome measures The prevalence of pregnancies with an NTD in the UK and the number of these pregnancies that would have been prevented if folic acid fortification had been implemented.

Results From 1991 to 2012, the prevalence of NTD pregnancies was 1.28 (95\% Cl 1.24 to 1.31$)$ per 1000 total births ( $19 \%$ live births, $81 \%$ terminations and $0.5 \%$ stillbirths and fetal deaths $\geq 20$ weeks' gestation). If the USA levels of folic acid fortification from 1998 onwards had been adopted in the UK, an estimated 2014 fewer NTD pregnancies would have occurred. Conclusions Failure to implement folic acid fortification in the UK has caused, and continues to cause, avoidable terminations of pregnancy, stillbirths, neonatal deaths and permanent serious disability in surviving children.

\section{INTRODUCTION}

In 1991, the Lancet published the report of the Medical Research Council (MRC) Vitamin Study randomised controlled trial, which showed that taking folic acid before conception reduced the risk of a neural tube defect (NTD) pregnancy by an estimated $72 \%{ }^{1}$ It is not possible to achieve a high enough daily intake of folate to provide such a reduction in risk from dietary modification alone; so, taking folic acid supplements or eating food fortified with folic acid is necessary. Mandatory fortification of flour with folic acid has been introduced in 78 countries, including the USA, Canada and Australia, but despite evidence that such fortification is effective, ${ }^{2-9}$ mandatory folic acid fortification of flour has not been introduced in the UK. In 1992, the UK Department of Health advised women to take folic acid supplements (in the form of tablets or capsules) before pregnancy to reduce their risk of an NTD pregnancy. ${ }^{10}$

\section{What is already known on this topic}

Folic acid has a substantial effect in preventing neural tube defects, but most women do not take folic acid supplements.

- Population-wide fortification of flour with folic acid is an effective preventive measure.

\section{What this study adds}

- An estimated 2000 pregnancies associated with a neural tube defect would have been prevented if the UK had adopted the same fortification regimen adopted in the USA from 1998.

- Fortification of flour with folic acid should be a priority UK public health policy.

The aim of this study was to determine the prevalence of pregnancies and live births with an NTD in the UK and to estimate the potential effect there would have been on the prevalence of NTDs if fortification of flour with folic acid had been implemented in 1998 as was done in the USA.

\section{METHODS}

Data on the number of diagnoses and terminations with an NTD are available from the British Isles Network of Congenital Anomaly Registers (BINOCAR). Although the registers do not cover the whole of the UK, these figures are considered to be more complete than those from the Office for National Statistics (ONS) ${ }^{11}$ and are submitted as part of the European Surveillance of Congenital Anomalies (EUROCAT), which spans a greater period than the data collation and publication initiated by BINOCAR in $2009 .{ }^{12}$ EUROCAT is a European network of population-based registries for the epidemiologic surveillance of congenital anomalies (http://www.eurocat-network.eu/) and surveys over 1.7 million births from 25 countries in Europe ${ }^{13}$ Data from BINOCAR registers about live births, late fetal deaths ( $>20$ weeks' gestation) and terminations of pregnancy due to fetal anomaly at any gestation (TOPFA) with an NTD were obtained from the EUROCAT website for 1991-2012, as this website allows bespoke prevalence tables to be obtained interactively. ${ }^{14}$ Data were available for all of Wales, but were only available in regions of 
England in which a congenital anomaly register (CAR) was active, and were not available for Scotland or Northern Ireland. From 1991 to 2012, eight regional CARs provided data to EUROCAT (see table 1). Details on the data and their collection are available at http://www.eurocat-network.eu/. Registers use multiple sources of information to ascertain cases, including maternity, neonatal and paediatric records; fetal medicine, cytogenetic, pathology and medical genetics records; specialist services including paediatric cardiology; and hospital discharge and child health records.

Anomalies were coded according to the EUROCAT guide 1.3. ${ }^{15}$ NTDs include anencephalus, encephalocele and spina bifida. Cases were coded as having encephalocele only if there was no mention of anencephalus. Similarly, cases were coded as having spina bifida only if there was no mention of anencephalus or encephalocele.

The annual change in prevalence of NTD pregnancies was estimated within each register over the time period during which the register was active. These annual changes were then combined to provide an overall estimate using a random effects multilevel Poisson regression model nested within registers. The total number of births covered by each regional CAR was the exposure variable, and these were available from the EUROCAT website. This model estimated the prevalence of NTDs in each two yearly period adjusted for the specific CARs. Similarly, a random effects multilevel logistic regression model nested within registers was used to model the proportion of pregnancies that ended in a termination. All analyses were performed in Stata V.12. ${ }^{16}$

The number of NTD diagnoses and births occurring in the whole of the UK in a year was estimated by multiplying the prevalence in the regions with registries by the total number of births in the UK in that year.

In the USA, mandatory fortification with $140 \mu \mathrm{g}$ of folic acid per $100 \mathrm{~g}$ of enriched cereal grain product was fully implemented in 1998, and has been estimated to provide $200 \mu \mathrm{g}$ of folic acid per day to women of childbearing age. ${ }^{17}$ Wald et al ${ }^{18}$ estimated that for the average serum folate concentration for young women in Britain $(5 \mathrm{ng} / \mathrm{mL})$, an increase in folic acid intake of $200 \mu \mathrm{g}$ per day would increase the average serum folate concentration by $1.88 \mathrm{ng} / \mathrm{L}$ and hence reduce the risk of NTDs by about $23 \%$. A recent paper assessing the extent of folic acid supplementation among almost half a million women in England has estimated that the proportion of women taking folic acid supplements declined from $39.6 \%$ in 1999 to $27.8 \%$ in $2012 .{ }^{19}$ This is in agreement with an additional study from the West Midlands in England, which reported on 111000 pregnant women of whom $25.5 \%$ took folic acid before pregnancy from 2009 to $2012 .^{20}$ In order to calculate a conservative estimate of the potential reduction in NTDs due to fortification, it was assumed that fortification would only have benefitted those women not taking supplements and that the reduction in risk would have been $23 \% .{ }^{18}$ For a conservative estimate, the higher proportions of women taking supplements from Bestwick et $a l^{19}$ (from 39.6\% to $27.8 \%$ ) were used rather than the $25.5 \%$ estimated from the West Midlands. ${ }^{20}$ For example, in $2012,27.8 \%$ of women took a folic acid supplement and therefore, the effect of fortification would be $(1-0.278) \times 0.23$ that is, a $17 \%$ reduction in pregnancies with an NTD.

\section{RESULTS}

Table 1 shows the prevalence of NTD pregnancies per 1000 births by register. From 1991 to 2012, the prevalence of NTD pregnancies was 1.28 (95\% CI 1.24 to 1.31 ) per 1000 total births and of NTD live births was 0.20 (0.16 to 0.25$)$ per 1000 live births. The proportion of affected pregnancies terminated was $81 \%$, and $0.5 \%$ were late stillbirths or fetal deaths $\geq 20$ weeks' gestation.

Figure 1 shows the prevalence of NTD pregnancies (live births, late fetal losses after 20 weeks' gestation and terminations with an NTD) from 1991 to 2012 in two yearly periods. Online supplementary appendix table 1 gives the annual prevalence of NTD pregnancies from 1991 to 2012. There was no statistically significant decrease in the prevalence in the 14 years from 1998 (the start of fortification in the USA) to $2012(-7 \%$; $95 \% \mathrm{CI}-17 \%$ to $+3 \%)$.

Figure 1 shows the prevalence of spina bifida (excluding anencephaly), anencephaly (with or without spina bifida) and encephalocele individually. Again, there was no statistically significant change in the prevalence of spina bifida $(-8 \% ; 95 \%$ CI $-21 \%$ to $+8 \%)$, anencephaly $(0 \% ;-15 \%$ to $+18 \%)$ and encephalocele $(-20 \% ;-43 \%$ to $+14 \%)$ from 1998 to 2012.

Table 2 shows that if fortification had been implemented at the level adopted by the USA from 1998 to 2012, there would have been an estimated 2014 fewer pregnancies affected with an NTD in the UK (1798 in England and Wales, 152 in Scotland and 64 in Northern Ireland). An estimated 21\% reduction in the prevalence of NTDs would have occurred, threefold greater than that observed.

\section{DISCUSSION}

Our results show that in the UK between 1998 and 2012, there was little, if any, change in the prevalence of pregnancies with

Table 1 Prevalence of pregnancies with an NTD and proportion of NTD pregnancies resulting in a termination of pregnancy by register

\begin{tabular}{lllll}
\hline Register & $\begin{array}{l}\text { Years of notification } \\
\text { to EUROCAT }\end{array}$ & $\begin{array}{l}\text { Number of pregnancies } \\
\text { with an NTD }\end{array}$ & $\begin{array}{l}\text { Prevalence of pregnancies with } \\
\text { an NTD per 1000 births (95\% Cl) }\end{array}$ & $\begin{array}{l}\text { Proportion of pregnancies (\%) with } \\
\text { an NTD resulting in a termination of } \\
\text { pregnancy (95\% Cl) }\end{array}$ \\
\hline South West England & $2005-2012$ & 446 & $1.1(1.0$ to 1.2$)$ & $82(79$ to 86$)$ \\
Thames Valley & $1991-2012$ & 398 & $1.2(1.1$ to 1.4$)$ & $82(79$ to 86$)$ \\
North West Thames & $1991-2004$ & 826 & $1.2(1.2$ to 1.3$)$ & $83(80$ to 86$)$ \\
East Midlands and South Yorkshire & $1998-2012$ & 1156 & $1.2(1.1$ to 1.2$)$ & $77(74$ to 79$)$ \\
Merseyside and Cheshire & $1995-1999$ & 183 & $1.3(1.1$ to 1.5$)$ & $82(76$ to 87$)$ \\
Wessex & $1994-2012$ & 668 & $1.3(1.2$ to 1.4$)$ & $86(84$ to 89$)$ \\
Northern England & $2000-2012$ & 603 & $1.4(1.3$ to 1.6$)$ & $79(76$ to 83$)$ \\
Wales & $1998-2012$ & 772 & $1.5(1.4$ to 1.6$)$ & $82(80$ to 85$)$ \\
Total & & $1.3(1.2$ to 1.3$)$ & $81(80$ to 82$)$ \\
\hline
\end{tabular}

EUROCAT, European Surveillance of Congenital Anomalies; NTD, neural tube defect. 
Figure 1 Prevalence of all neural tube defects (NTDs), spina bifida, anencephaly and encephalocele diagnoses (live births, late fetal losses after 20 weeks' gestation and terminations) per 1000 live births; eight regional congenital anomaly registers in the UK: 1991-2012.

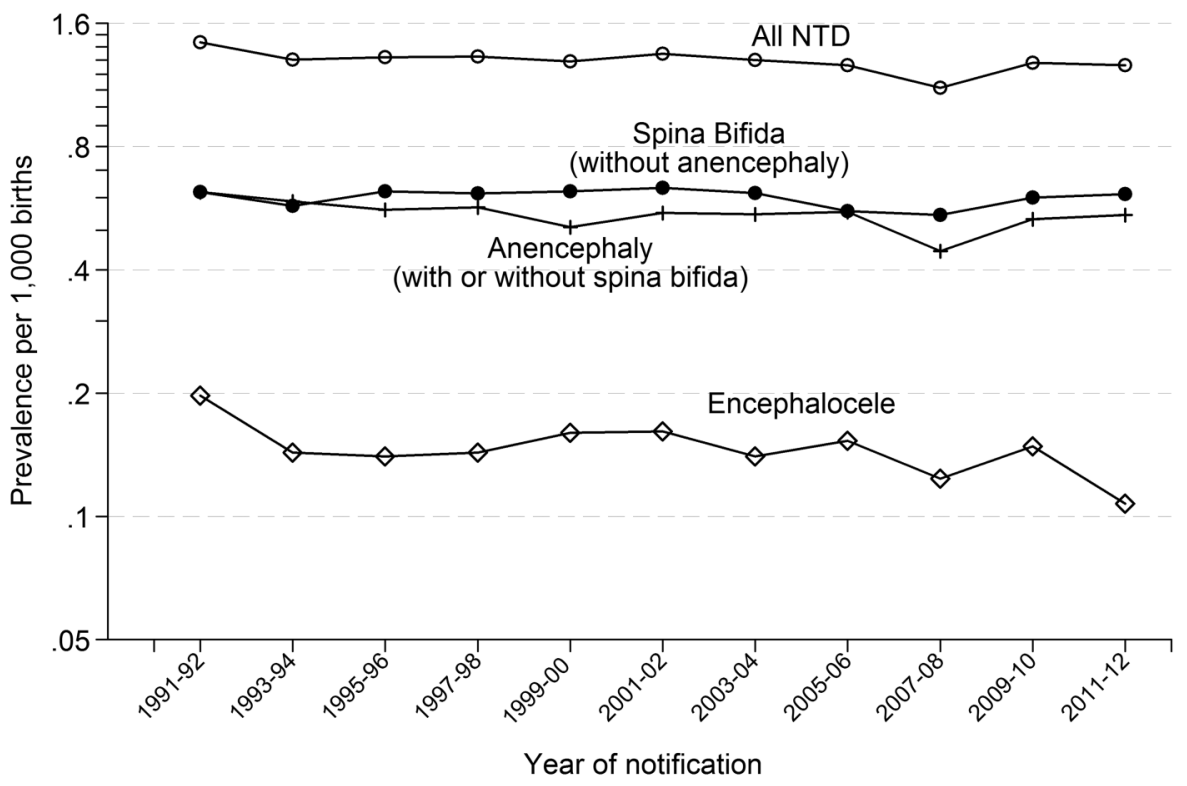

an NTD, while in the USA, quickly following the introduction of mandatory fortification of flour with folic acid in 1998, there was an approximate $23 \%$ reduction in the occurrence of affected births. $^{2-4}$ Given the evidence from the MRC Vitamin Study ${ }^{1}$ regarding the efficacy of folic acid in preventing NTDs, the failure of Britain to fortify flour with folic acid has had significant consequences.

Table 2 Estimation of the number of pregnancies with a neural tube defect (NTD) that would have been prevented if folic acid fortification of flour had been implemented in 1998 in the UK

\begin{tabular}{|c|c|c|c|c|}
\hline $\begin{array}{l}\text { Year of } \\
\text { notification }\end{array}$ & $\begin{array}{l}\text { Number of } \\
\text { pregnancies } \\
\text { with an } \\
\text { NTD* }\end{array}$ & $\begin{array}{l}\text { Proportion } \\
\text { of women } \\
\text { taking } \\
\text { folic acid } \\
\text { before } \\
\text { pregnancy } \\
(\%) \dagger\end{array}$ & $\begin{array}{l}\text { Estimated } \\
\text { additional } \\
\text { percentage } \\
\text { reduction in } \\
\text { women if } \\
\text { folic acid } \\
\text { fortification } \\
\text { implemented } \\
\text { from } 1998(\%)\end{array}$ & $\begin{array}{l}\text { Number of } \\
\text { pregnancies } \\
\text { with an NTD } \\
\text { that would } \\
\text { have been } \\
\text { prevented } \\
\text { by folic acid } \\
\text { fortification }\end{array}$ \\
\hline & $A$ & B & $C=(1-B / 100) \times 23$ & $\mathrm{AxC}$ \\
\hline 1998 & 936 & 39.6 & $0 \ddagger$ & 0 \\
\hline 1999 & 898 & 39.6 & 14 & 125 \\
\hline 2000 & 898 & 39.6 & 14 & 125 \\
\hline 2001 & 884 & 39.6 & 14 & 123 \\
\hline 2002 & 915 & 35.6 & 15 & 136 \\
\hline 2003 & 931 & 35.6 & 15 & 138 \\
\hline 2004 & 910 & 35.6 & 15 & 135 \\
\hline 2005 & 905 & 31.8 & 16 & 142 \\
\hline 2006 & 931 & 31.8 & 16 & 146 \\
\hline 2007 & 875 & 31.8 & 16 & 137 \\
\hline 2008 & 863 & 29.9 & 16 & 139 \\
\hline 2009 & 1019 & 29.9 & 16 & 164 \\
\hline 2010 & 1022 & 29.9 & 16 & 165 \\
\hline 2011 & 1034 & 27.8 & 17 & 172 \\
\hline 2012 & 1012 & 27.8 & 17 & 168 \\
\hline $\begin{array}{l}\text { Total } \\
\text { (1998-2012) }\end{array}$ & & & & 2014 \\
\hline
\end{tabular}

*From online supplementary appendix table 1.

tFrom ref. 19.

¥Conservative assumption of no reduction in the first year of fortification.
The recent evidence that only $28 \%$ of pregnant women in England in 2012 took folic acid supplements at the correct time indicates that, in practice, recommending folic acid supplementation is largely ineffective. ${ }^{19}$ In addition, a recent report showed that the median level of serum folate in women from the UK aged 16-49 was $7.1 \mathrm{ng} / \mathrm{mL}$ in samples obtained from 2008 to $2012 .^{21}$ This is in comparison with the median levels of $5 \mathrm{ng} / \mathrm{mL}$ observed in the samples collected from 1983 to 1991 from pregnant women in the MRC Vitamin Study; ${ }^{1}$ an increase of only $2.1 \mathrm{ng} / \mathrm{mL}$ over 20 years with an estimated $22 \%$ of women still having a serum folate $<5 \mathrm{ng} / \mathrm{mL} .^{21}$ The absence of any material change in NTD rates in the past 14 years is, therefore, not surprising. Our study demonstrates that an estimated threefold greater reduction in the prevalence of NTDs would have been achieved if fortification of flour with folic acid had been adopted. In Chile, the level of flour fortification adopted is higher than that in the USA $(2.2 \mu \mathrm{g} / 100 \mathrm{~g}$ flour vs $1.4 \mu \mathrm{g} / 100 \mathrm{~g}) .^{22}$ If this level of fortification had been adopted, about double (3500) the number of pregnancies with an there would have been an estimated 36\% reduction in the prevalence of NTDs. Given the known benefits, there is no reason not to adopt the level of fortification introduced in Chile in all countries throughout the world.

Folic acid intake either in the form of supplements or in fortified flour is remarkably safe. It is a water-soluble vitamin that can be readily excreted, and while there has been speculation over possible hazards, notably cancer, none have been demonstrated. In particular, a large meta-analysis of randomised trials involving the use of folic acid supplements failed to provide any suggestion of a cancer risk. ${ }^{23}$ Therefore, health authorities should not specify a maximum daily intake, as this minimises the fortification level due to concerns of a small proportion of the population exceeding this maximum daily intake. In Chile, such concerns led to the unwarranted reduction of fortification level in 2012 (2.2 to $1.8 \mu \mathrm{g}$ folic acid/100 g wheat flour). ${ }^{24} \mathrm{It}$ has been demonstrated that the higher the dose of folic acid the higher the degree of protection from NTDs, and therefore, health authorities should seek to adopt the highest fortification level judged to be acceptable. ${ }^{18}$ to be an extremely cost-effective way to provide this nutrient affected baby would have resulted in an unaffected baby, and

Mandatory food fortification with folic acid has been shown 
during the periconceptional period and reduce the number of children affected by NTDs. ${ }^{8} 2425$

An advantage of our study is that it was based on $36 \%$ of all births in England and Wales. There is no reason to believe that the prevalence of NTD pregnancies in regions in England not covered by CARs will differ from the regions covered by CARs, particularly with such a large sample (36\%). We used data from CARs rather than data from the ONS, which have been shown to be incomplete and which ceased congenital anomaly data collection in 2011. The data from the CARs are all coded consistently, and have been shown to have high ascertainment rates due to obtaining notifications from multiple sources. ${ }^{11}$ Information on whether the women who had had an affected pregnancy took folic acid supplements before and during the first trimester of pregnancy would have been very informative, but unfortunately was not available.

The number of pregnancies with an NTD that would have been prevented by folic acid fortification is based on the estimate that the risk of an NTD pregnancy will be reduced by $23 \%$ in women who are not taking a folic acid supplement. The $23 \%$ was derived from a model based on the synthesis of many studies of the dose response of women taking folic acid and the risk of NTD pregnancies according to serum folate at levels close to the levels of fortification being considered. The model accurately predicted the results from the MRC Vitamin Study when much higher levels of folic acid were taken in the form of supplements of $4 \mu \mathrm{g} /$ day and also accurately predicted the observed reduction in the USA. The $23 \%$ is, therefore, reasonably reliable.

The proportions of women taking folic acid before pregnancy are based on a study of nearly half a million women and hence are precise estimates (their $95 \% \mathrm{CI}$ are on average under $1 \%$ in width). If an estimated risk reduction $10 \%$ lower than the original 23\% (ie, 21\% instead of 23\%) and the upper 95\% CI for the proportions taking folic acid are used, the estimated total number of pregnancies with an NTD that could have been prevented will still be over 1800 compared with the 2000 originally estimated, indicating the robustness of the estimates.

The failure to implement folic acid fortification has resulted in the conception of an estimated 2000 pregnancies affected with an NTD in the UK from 1998 to 2012. This failure will continue to result in an estimated additional 150 affected pregnancies each year. Of these, about half will be due to spina bifida without anencephaly (see figure 1), and, in the absence of termination of pregnancy, nearly all of these would result in the birth of individuals with serious disability. Therefore, the failure to fortify resulted in an estimated 1000 people with serious disability and this is continuing with about 75 more individuals with disability being born every year. In comparison, the thalidomide epidemic, in total caused about 500 people to be disabled in the UK. ${ }^{26}$ Justifiably, steps were introduced to immediately halt the epidemic, and regulatory precautions were introduced to avoid another similar epidemic. Unfortunately, no such sense of urgency has been applied to the prevention of spina bifida. It is illogical to take preventive public health action to avoid a drug-induced congenital anomaly, but to largely ignore action in relation to a congenital anomaly which can be prevented by vitamin fortification of flour, when the failure to act has resulted in, and continues to result in, many more serious cases. It is a public health failure that Britain has not implemented the fortification of flour with folic acid for the prevention of spina bifida and other NTDs.

Contributors JKM: conceived the study, obtained the data, performed the analysis, wrote the paper. JR: conceived the study. ESD, JJK, AS, DT, DW and BW: contributed to the paper. NJW: conceived the study, contributed to the paper. All authors commented on the draft paper and gave final approval for submission.

\section{Competing interests None declared.}

Provenance and peer review Not commissioned; externally peer reviewed.

Open Access This is an Open Access article distributed in accordance with the Creative Commons Attribution Non Commercial (CC BY-NC 4.0) license, which permits others to distribute, remix, adapt, build upon this work non-commercially, and license their derivative works on different terms, provided the original work is properly cited and the use is non-commercial. See: http://creativecommons.org/ licenses/by-nc/4.0/

\section{REFERENCES}

1 MRC Vitamin Study Research Group. Prevention of neural tube defects: results of the Medical Research Council Vitamin Study. Lancet 1991;338:131-7.

2 Mathews TJ. Trends in spina bifida and anencephalus in the United States, 19912006. http://www.cdc.gov/nchs/products/pubs/pubd/hestats/spine_anen.htm (accessed 27 Nov 2014).

3 Honein MA, Paulozzi LJ, Mathews TJ, et al. Impact of folic acid fortification of the US food supply on the occurrence of neural tube defects. JAMA 2001;285:2981-6.

4 Williams LJ, Mai CT, Edmonds LD, et al. Prevalence of spina bifida and anencephaly during the transition to mandatory folic acid fortification in the United States. Teratology 2002;66:33-9.

5 Flour Fortification Initiative. Global Progress. http://www.ffinetwork.org/global_ progress/. (accessed 18 Dec 2014).

6 Lopez-Camelo JS, Orioli IM, de Graca Dutra M, et al. Reduction of birth prevalence rates of neural tube defects after folic acid fortification in Chile. Am J Med Genet $A$ 2005; 135:120-5

7 De Wals P, Tairou F, Van Allen MI, et al. Reduction in neural tube defects after folic acid fortification in Canada. New Engl J Med 2007;357:135-42.

8 Sayed AR, Bourne D, Pattinson R, et al. Decline in the prevalence of neural tube defects following folic acid fortification and its cost-benefit in South Africa. Birth Def Res A Clin Mol Teratol 2008;82:211-16.

9 Collins JS, Atkinson KK, Dean JH, et al. Long term maintenance of neural tube defects prevention in a high prevalence state. J Pediatr 2011;159:143-9.

10 Expert Advisory Group. Folic acid and the prevention of neural tube defects. London: Department of Health, 1992.

11 Boyd PA, Armstrong B, Dolk $\mathrm{H}$, et al. Congenital anomaly surveillance in Englandascertainment deficiencies in the national system. BMJ 2005;330:27.

12 http://www.binocar.org (accessed 18 Dec 2014).

13 Dolk H. EUROCAT: 25 years of European surveillance of congenital anomalies. Arch Dis Child Fetal Neonatal Ed 2005:90:F355-8.

14 http://www.eurocat-network.eu/accessprevalencedata/prevalencetables (accessed 18 Dec 2014).

15 EUROCAT: Guide 1.3 and reference documents. Instructions for the registration and surveillance of congenital anomalies. http://www.eurocat-network.eu/content/ EUROCAT-Guide-1.3.pdf (accessed 18 Dec 2014)

16 StatCorp, 2011. Stata Statistical Software: Release 12. College Station, Texas: StataCorp LP.

17 Yang QH, Carter HK, Mulinare J, et al. Race-ethnicity differences in folic acid intake in women of childbearing age in the United States after folic acid fortification: findings from the National Health and Nutrition Examination Survey, 2001-2002. Am J Clin Nutr 2007:85:1409-16.

18 Wald NJ, Law MR, Morris JK, et al. Quantifying the effect of folic acid. Lancet 2001;358:2069-73.

19 Bestwick JP, Huttly WJ, Morris JK, et al. Prevention of neural tube defects: a cross-sectional study of the uptake of folic acid supplementation in nearly half a million women. PLOS ONE 2014;9:e89354.

20 Hodgetts VA, Morris RK, Francis A, et al. Effectiveness of folic acid supplementation in pregnancy on reducing the risk of small-for-gestational age neonates: a population study, systematic review and meta-analysis. BJOG 2015;122:478-90.

21 National Diet and Nutrition Survey Rolling Programme (NDNS RP) Supplementary report: blood folate results for the UK as a whole, Scotland, Northern Ireland (Years 1 to 4 combined) and Wales (Years 2 to 5 combined) (2008/2009-2011/2012)

22 Hertrampf E, Cortés F. National food-fortification program with folic acid in Chile. Food Nutr Bull 2008;29(2 Suppl):S231-7.

23 Vollset SE, Clarke R, Lewington S, et al. Effects of folic acid supplementation on overall and site-specific cancer incidence during the randomised trials: meta-analyses of data on 50000 individuals. Lancet 2013;6736):62001-7.

24 Cortes F, Mellado C, Pardo RA, et al. Wheat flour fortification with folic acid: Changes in neural tube defects rates in Chile. Am J Med Genet A 2012;158:1885-90.

25 Grosse SD, Waitzman NJ, Romano PS, et al. Re-evaluation the benefits of folic acid fortification in the United Sates: economic analysis, regulation and public health. Am J Public Health 2005;95:1917-22.

26 http://www.thalidomideuk.com/\#!campaign-info/c16uz (accessed 20 May 2015). 